\title{
Board 104: Academic Pathways of Black Men and Women in Electrical and Mechanical Engineering
}

\section{Dr. Marisa K. Orr, Clemson University}

Marisa K. Orr is an Assistant Professor in Engineering and Science Education with a joint appointment in the Department of Mechanical Engineering at Clemson University. Her research interests include student persistence and pathways in engineering, gender equity, diversity, and academic policy. Dr. Orr is a recipient of the NSF CAREER Award for her research entitled, "Empowering Students to be Adaptive Decision-Makers."

\section{Dr. Catherine Mobley, Clemson University}

Catherine Mobley, Ph.D., is a Professor of Sociology at Clemson University. She has over 30 years experience in project and program evaluation and has worked for a variety of consulting firms, non-profit agencies, and government organizations, including the Rand Corporation, the American Association of Retired Persons, the U.S. Department of Education, and the Walter Reed Army Institute of Research. Since 2004, she been a member of the NSF-funded MIDFIELD research project on engineering education; she has served as a Co-PI on three research projects, including one on transfer students and another on student veterans in engineering.

\section{Dr. Catherine E. Brawner, Research Triangle Educational Consultants}

Catherine E. Brawner is President of Research Triangle Educational Consultants. She received her Ph.D.in Educational Research and Policy Analysis from NC State University in 1996. She also has an MBA from Indiana University (Bloomington) and a bachelor's degree from Duke University. She specializes in evaluation and research in engineering education, computer science education, and technology education. Dr. Brawner is a founding member and former treasurer of Research Triangle Park Evaluators, an American Evaluation Association affiliate organization and is a member of the American Educational Research Association and American Evaluation Association, in addition to ASEE. Dr. Brawner is also an Extension Services Consultant for the National Center for Women in Information Technology (NCWIT) and, in that role, advises computer science and engineering departments on diversifying their undergraduate student population. She remains an active researcher, including studying academic policies, gender and ethnicity issues, transfers, and matriculation models with MIDFIELD as well as student veterans in engineering. Her evaluation work includes evaluating teamwork models, broadening participation initiatives, and S-STEM and LSAMP programs.

\section{Dr. Rebecca Brent, Education Designs, Inc}

Rebecca Brent is President of Education Designs, Inc., a consulting firm located in Chapel Hill, N.C. She is a certified program evaluator and a faculty development consultant. Brent received her B.A. from Millsaps College in Jackson, Miss., her M.Ed. from Mississippi State University, and her Ed.D. from Auburn University. She was an Associate Professor of education at East Carolina University before starting her consulting firm in 1996.

\section{Dr. Richard A. Layton P.E., Rose-Hulman Institute of Technology}

Richard Layton is a Professor of Mechanical Engineering at Rose-Hulman Institute of Technology. He received a B.S. from California State University, Northridge, and an M.S. and Ph.D. from the University of Washington. His areas of scholarship include student teaming, longitudinal studies of engineering undergraduates, and data visualization. He is a founding developer of the CATME system, a free, webbased system that helps faculty assign students to teams and conduct self- and peer-evaluations. He is a co-author of the Engineering Communication Manual, an undergraduate text published in 2016 by Oxford Univ. Press. He can occasionally be found playing guitar at a local open mic. 


\title{
Academic Pathways of Black Men and Women in Electrical and Mechanical Engineering
}

\begin{abstract}
We present a visual, quantitative analysis of the academic pathways of Black men and women who enroll in Electrical Engineering (EE) or Mechanical Engineering (ME) at any point during their undergraduate experience $(\mathrm{N}=4816)$. Our research provides evidence that more Black students choose $\mathrm{EE}$ than $\mathrm{ME}$, in contrast to national data for all races that show that more students major in ME than EE. While more Black students initially enroll in EE overall, ME attracts a larger proportion of its Black students from other majors and retains a larger fraction. Black women are particularly persistent in ME (58\%). Most Black students who leave EE or ME leave the institution without a degree. Seventy-eight percent of Black men and $65 \%$ of Black women who leave ME leave the institution without a degree. Of those leaving EE, 74\% of Black men and $64 \%$ of Black women leave the institution without a degree. This examination of quantitative differences between disciplines lays a foundation for qualitative study through indepth student interviews of Black students in these majors.
\end{abstract}

\section{Introduction}

The phenomena of low enrollment and persistence of Black students in engineering disciplines are affected by an interwoven tangle of individual, institutional, and disciplinary climate factors. Our multi-pronged study seeks to untangle these influences by combining large-scale quantitative analysis and in-depth student interviews with key informant interviews and profiles of relevant school policies and programs. Black students experience diverse pathways into, through, and out of engineering that vary according to discipline. For this project, we have selected one discipline in which Black students enroll at an above-average rate, Electrical Engineering (EE), and one discipline in which Black students persist at an above-average rate, Mechanical Engineering $(\mathrm{ME})$. Computer Engineering $(\mathrm{CpE})$ and $\mathrm{EE}$ are often within the same department, so qualitative interviews include $\mathrm{CpE}$ students, however, $\mathrm{CpE}$ is not addressed in this paper because it was not offered at all the study institutions during the period of available data. We have selected four schools with a large number of Black students in the study disciplines. In this paper, we present one aspect of the quantitative analysis: examining the academic trajectories of Black men and women who enroll in one of these disciplines at any point during their undergraduate experience. Visualizing these pathways can help lay the groundwork for conducting and interpreting student interviews as well as identifying barriers that may disproportionately affect Black men or women.

\section{Background}

\section{The need to diversify engineering}

In recent decades, the emphasis on increasing the number of engineering graduates has been coupled with greater concern about the lack of diversity in engineering fields. Research has identified the benefits of identity diversity (e.g., race, ethnicity, gender, socioeconomic status, etc.) in engineering education, including more innovative groups [1], greater engagement in active thinking processes, growth in intellectual engagement and motivation, and an increase in academic skills $[2,3]$. A variety of educational policies and programs have been initiated to 
boost participation and increase graduation rates of under-represented minorities (URMs) in engineering education.

However, despite numerous calls to diversify engineering [4], [5] and the initiation of these policies and programs, there is still a lack of diversity in the proportion of engineering bachelor's degrees awarded to people of color that is then reflected in the profession [6]. The representation of minorities among engineering graduates is not keeping pace with the changing demographic landscape of the general population or undergraduate population of the 21 st century. The majority of undergraduate engineering degrees in the U.S. are awarded to students who identify as White. In 2015, White students received $65 \%$ of the engineering Bachelor's degrees, Asian students over $13 \%$, and Hispanic students nearly $11 \%$. However, Black students received only $4 \%$ of all engineering degrees [7], an increase from 2014 and reversing a nine-year decline from $5.3 \%$ in 2005 to $3.5 \%$ in 2014 [8]. Our research quantifies the pathways of Black engineering students through the $\mathrm{EE}$ and $\mathrm{ME}$ disciplines as a precursor to our related qualitative research which seeks to explain these patterns.

\section{Differences across engineering majors}

While there are commonalities across many engineering fields, Lattuca and colleagues' [9] research demonstrated substantial differences across engineering majors in teaching approaches and students' experiences. Recent investigations explore the idea of the culture of engineering education and the need to understand this culture before we can effect systemic change [10], [11]. For example, Godfrey [12] showed that different engineering disciplines exhibited different cultures, or "cultures within cultures," affecting the participation of women.

Our mixed-methods project explores the different disciplinary cultures of EE and ME as these fields provide a sharply contrasting picture of engineering matriculation, persistence, and attrition for Black students. EE is one of the largest and oldest engineering disciplines, dating back to the 1880s [13]. EE attracts an above-average percentage of Black males and females compared to other engineering disciplines [14]. ME dates back to the 19th century and is currently the largest engineering discipline [15], awarding $23.8 \%$ of engineering degrees in the U.S. and Canada in 2015 [7]. ME attracts a smaller percentage of Black engineering students but is better at retaining them (especially females) to graduation [16].

\section{Methods}

This study utilizes the Multiple-Institution Database For Investigating Engineering Longitudinal Development (MIDFIELD) to uncover the academic trajectories of Black men and women in Electrical and Mechanical Engineering. MIDFIELD includes student-unit academic data for four of the top 15 schools in the U.S. in number of Black engineering graduates [7], which allows us to take an intersectional approach, recognizing that Black men may have very different experiences than Black women in these predominantly White and male-dominated fields. For this paper, we focus on the four schools where interviews are also being conducted as part of the qualitative phase of this study. These institutions allowed students to indicate a specific engineering discipline as their first major during the period studied (1987-2004).

Sankey flow diagrams are used to visualize how students move into, out of, and through these engineering disciplines. These diagrams depict movement through a system, with the widths of 
the arrows representing the number of students following a particular path. We examine the majors that Black students enter after leaving EE and ME, and the majors that they come from when they migrate into EE and ME. We define "ever EE" and "ever ME," and as students who ever declared electrical or mechanical engineering, respectively. Conforming to IPEDS (Integrated Postsecondary Education Data System) standards, we use the 6-year point to investigate outcomes and only include students for whom six calendar years of data after matriculation are available. Including all the data for each student would bias the results in favor of earlier cohorts who have had more time to return and using a longer window would eliminate the more recent cohorts from the study. There are several groups of students for whom the 6-year point is not an accurate representation of their final educational outcome: those who are continuing at year 6, but eventually drop out (we know of 58 in engineering and 24 in other majors), and those who have stopped out in year 6 but later returned (we know of 145 who returned to engineering and 66 who returned to other majors).

\section{Sample}

We investigate the 4816 Black students at the study institutions who ever majored in ME or EE as shown in Table 2. The first two columns sum to more than the total column because 106 students appear in both the Ever ME and Ever EE columns. This means that they declared each major at a different point in their academic trajectory.

Table 1. Study Sample

\begin{tabular}{|l|r|r|r|r|}
\hline \multicolumn{1}{|c|}{ Gender } & Ever ME & \multicolumn{1}{c|}{ Ever EE } & \multicolumn{1}{c|}{ Total } & \multicolumn{1}{c|}{ Ever EE/ Ever ME } \\
\hline Women & 481 & 908 & 1363 & 1.9 \\
\hline Men & 1351 & 2182 & 3453 & 1.6 \\
\hline Total & 1832 & 3090 & 4816 & 1.7 \\
\hline
\end{tabular}

\section{Results}

Nationally, across all races, less than half as many students graduate in EE as in ME [17]. However, among Black students in our study, the relationship is reversed, with 1.7 times as many Black students choosing EE than choosing ME (Table 2).

\section{Electrical Engineering}

The pathways of Black students who ever enrolled in electrical engineering are shown in Figure 1. On the left is the starting major, grouped into EE, other engineering disciplines (Other-ENG), and non-engineering disciplines (Non-ENG). The darker bands represent men and the lighter bands represent women. The width of each band represents the number of students on that path. Year 6 destinations are depicted on the right and include students who either graduated in or were continuing in EE, another engineering discipline, or a non-engineering discipline six years after matriculation or for whom the sixth-year destination is "Left Inst." The Left Inst. category indicates that the student left the institution without a degree. They may have transferred, dropped out, or stopped out. Counts are summarized in Table 3. 


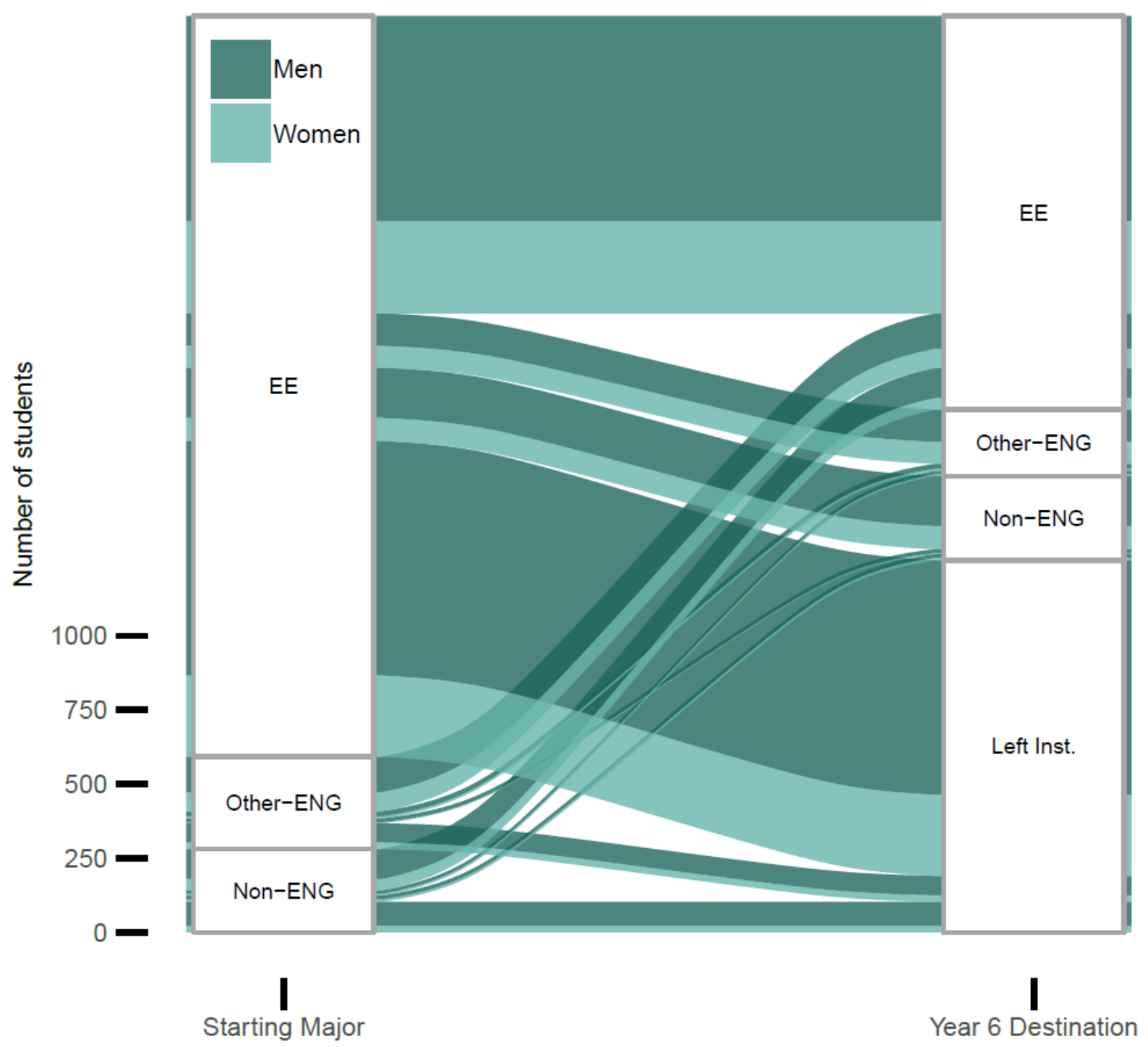

Figure 1. Black students ever enrolled in Electrical Engineering

Table 2. Black men and women ever enrolled in EE by Starting Major and Year 6 Destination

\begin{tabular}{|l|c|r|r|r|r|r|r|r|}
\hline \multirow{4}{*}{$\begin{array}{c}\text { Year } \\
\text { Destination }\end{array}$} & \multicolumn{9}{|c|}{ Starting Major } \\
\cline { 2 - 9 } & \multicolumn{6}{|c|}{ Men } & \multicolumn{4}{c|}{ Women } \\
\cline { 2 - 9 } & EE & Other-ENG & Non-ENG & Total & EE & Other-ENG & Non-ENG & Total \\
\hline EE & 692 & 119 & 101 & 912 & 311 & 65 & 39 & 415 \\
\hline Other-ENG & 109 & 17 & 11 & 137 & 74 & $<10^{*}$ & $<10^{*}$ & 87 \\
\hline Non-ENG & 169 & 13 & 13 & 195 & 78 & $<10^{*}$ & $<10^{*}$ & 89 \\
\hline Left Inst. & 791 & 65 & 82 & 938 & 274 & 22 & 21 & 317 \\
\hline Grand Total & 1761 & 214 & 207 & 2182 & 737 & 97 & 74 & 908 \\
\hline
\end{tabular}

*ranges are reported to protect student anonymity 
As shown by the large EE box on the left side of Figure 1, most Black students who ever enroll in EE choose it as their first major, but a significant portion start in other engineering majors $(10 \%)$ or even non-engineering majors $(9 \%)$ and many of them graduate in EE. The thickness of the light green bands shows that almost $30 \%$ of Black students starting in EE are women, well above the national average of $13.7 \%$ for all races in electrical engineering [17]. Overall, the Year 6 Destination EE box is slightly taller than the Left Inst. box, meaning that more Black students will persist in EE than leave the institution without a degree. From Table 3, we see this pattern is driven by the women. At six years, more Black women who ever majored in EE persisted in EE than left the institution. Conversely, more Black men left the institution than persisted in EE, at six years. Black women who left EE were more likely to switch majors and persist than Black men. Nearly three-fourths of Black men who leave EE leave the institution without a degree compared to $64 \%$ of Black women. Nearly $46 \%$ of Black women and $42 \%$ of Black men persisted in EE.

\section{Mechanical Engineering}

The pathways of Black men and women who ever enrolled in mechanical engineering are displayed in Figure 2 and summarized quantitatively in Table 4. 


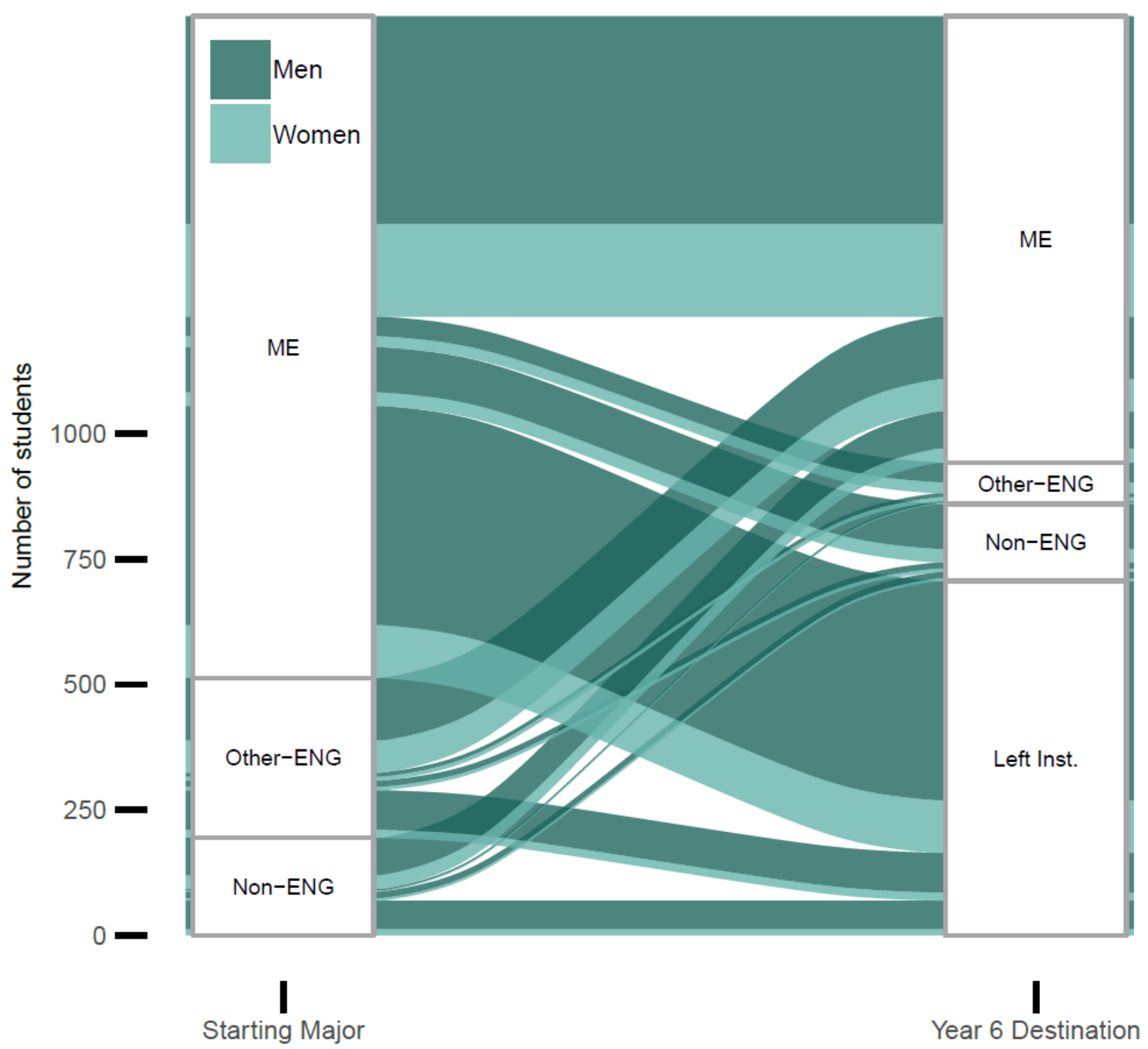

Figure 2. Black students ever enrolled in Mechanical Engineering.

Table 3. Black men and women ever enrolled in ME by Starting Major and Year 6 Destination

\begin{tabular}{|l|r|r|r|r|r|r|r|r|}
\hline \multirow{4}{*}{$\begin{array}{c}\text { Year 6 } \\
\text { Destination }\end{array}$} & \multicolumn{9}{|c|}{ Starting Major } \\
\cline { 2 - 9 } & \multicolumn{4}{|c|}{ Men } & \multicolumn{4}{c|}{ Women } \\
\cline { 2 - 9 } & ME & Other-ENG & Non-ENG & Total & ME & Other-ENG & Non-ENG & Total \\
\hline ME & 414 & 125 & 74 & 613 & 185 & 64 & 28 & 277 \\
\hline Other-ENG & 39 & $<10^{*}$ & $<10^{*}$ & 50 & 22 & $<10^{*}$ & $<10^{*}$ & 32 \\
\hline Non-ENG & 90 & $10-20^{*}$ & $10-20^{*}$ & 115 & 27 & $<10^{*}$ & $<10^{*}$ & 39 \\
\hline Left Inst. & 437 & 79 & 57 & 573 & 105 & 16 & 12 & 133 \\
\hline Total & $\mathbf{9 8 0}$ & $\mathbf{2 2 4}$ & $\mathbf{1 4 7}$ & $\mathbf{1 3 5 1}$ & $\mathbf{3 3 9}$ & $\mathbf{9 5}$ & $\mathbf{4 7}$ & $\mathbf{4 8 1}$ \\
\hline
\end{tabular}

*ranges are reported to protect student anonymity 
While the largest group of Black students who ever enrolled in ME started there, many also came from other engineering (17\%) and non-engineering (11\%) majors. One quarter of Black students starting in ME were women. More than twice as many Black women persisted in ME as left the institution, while Black men were more evenly split between the two outcomes. Those who leave ME tend to leave the institution altogether rather than changing majors. This is especially true of Black men who leave ME, $78 \%$ of whom leave the institution without a degree, compared to $65 \%$ of Black women who leave ME. Overall, $45 \%$ of Black men and $58 \%$ of Black women who enroll in ME persist in ME.

\section{Limitations}

Computer engineering was introduced into the curriculum at two of the four schools in this study in the early 2000's and therefore there were few students who had the full six years available to measure outcomes in the initial dataset. A time lag in data collection plus an additional six-year lag waiting for outcomes limits the current work in that $\mathrm{CpE}$ could not be included and that the results are historical representations that may not hold true for current students. The MIDFIELD dataset is currently being updated with more recent academic years for the original MIDFIELD partner schools which will allow us to add computer engineering to the analysis and contrast these academic pathways with both electrical and mechanical engineering academic pathways.

\section{Discussion, Conclusions, and Future work}

Confirming earlier research with a larger portion of the MIDFIELD dataset [14], [16], these results show that EE is particularly good at attracting Black students to the discipline but not particularly good at retaining them. By contrast, ME does not attract as many Black students as does EE, but retains them at a higher rate. Additionally, we see that when Black men leave Mechanical or Electrical Engineering, they are most likely to leave the institution without a degree. This raises many questions for future investigation. Using MIDFIELD, we will further explore the timing of the departures and GPA or academic status at the time of departure.

Research has shown that departure decisions due to poor institutional fit often happen in the first 2-6 weeks [18]. This type of departure would call for different interventions than if departures resulted from academic trouble or poor fit with one's major. One potential approach to improving outcomes for these students is to provide more opportunities for exploring academic majors, even after a major has been declared. Student-centric advising (rather than major- or department-centric) can help guide students to consider all of their options.

The qualitative portion of our project is designed to shed light on the reasons for some of the phenomena observed in the quantitative analysis reported here. Our interviews of key informants at our study institutions will provide deeper information about the contextual, policy, and programmatic factors that may influence student academic pathways and outcomes. Our in-depth interviews with students who remain in these majors and those who switch to other majors will help us to better understand what factors contribute to retention and attrition. Unfortunately, we do not have access to students who have left the institution altogether, so even those findings may not capture their full experience. Triangulation across multiple types and sources of data will allow us to build a robust picture of the experience of Black men and Black women in these engineering disciplines, which will in turn help inform policy and direct resources appropriately. 


\section{Acknowledgements}

This material is based upon work supported by the National Science Foundation under Grant No.

1734347. Any opinions, findings, and conclusions or recommendations expressed in this material are those of the authors and do not necessarily reflect the views of the National Science Foundation. The authors would like to thank Cindy Waters for her contributions early in this project.

\section{References Cited}

[1] S. E. Page, The difference: How the power of diversity creates better groups, firms, schools, and societies, Princeton, NJ: Princeton University Press, 2007.

[2] P. Gurin, "The compelling need for diversity in education," U.S. District Court, Eastern District of Michigan, Civil Action No. 97-75231, Ann Arbor, MI, 1999.

[3] National Academy of Sciences, National Academy of Engineering, and Institute of Medicine, Expanding underrepresented minority participation: America's science and technology talent at the crossroads, Washington, DC: The National Academies Press, 2011.

[4] National Academy of Engineering, Committee on Public Understanding of Engineering Messages, Changing the conversation: Messages for improving public understanding of engineering, Washington, DC: National Academies Press, 2008.

[5] Institute of Medicine, National Academy of Sciences, and National Academy of Engineering, Rising above the gathering storm: Energizing and employing America for a brighter economic future, Washington, DC: The National Academies Press, 2007.

[6] National Center for Education Statistics, "Bachelor's degrees conferred by postsecondary institutions, by race/ethnicity and field of study, 2011-12 and 2012-13, Table 322.30," 2014. [Online]. Available:

https://nces.ed.gov/programs/digest/d14/tables/dt14_322.30.asp?current=yes. [Accessed 6 September 2015].

[7] B. L. Yoder, Engineering by the Numbers, Washington, DC: American Society for Engineering Education, 2016.

[8] B. L. Yoder, Engineering by the Numbers, Washington, DC: American Society for Engineering Education, 2015.

[9] L. R. Lattuca, P. Terenzini, B. Harper and A. Yin, "Academic environments in detail: Holland's theory at the subdiscipline level," Research in Higher Education, vol. 51, no. 1, pp. 21-39, 2010.

[10] E. Godfrey and L. Parker, "Mapping the cultural landscape in engineering education," Journal of Engineering Education, vol. 99, no. 1, pp. 5-22, 2010.

[11] R. Stevens, D. Amos, A. Jocuns and L. Garrison, "Engineering as lifestyle and a meritocracy of difficulty: Two pervasive beliefs among engineering students and their possible effects," in Proceedings of the American Society for Engineering Education Annual Conference, Honolulu, HI, 2007.

[12] E. Godfrey, "Cultures within cultures: Welcoming or unwelcoming for women?," in Proceedings of the 2007 ASEE Annual Conference, Honolulu, HI, 2007.

[13] F. E. Terman, "A brief history of electrical engineering education," Proceedings of the IEEE, vol. 86, no. 8, pp. 1792-1800, 1998. 
[14] S. M. Lord, R. A. Layton and M. W. Ohland, "Multi-institution study of student demographics and outcomes in electrical and computer engineering in the U.S.A.," IEEE Transactions on Education, vol. 58, no. 3, pp. 141-150, 2015.

[15] ASME, “About ASME,” [Online]. Available: http://www.asme.org/about-asme. [Accessed 27 August 2015].

[16] S. M. Lord, R. A. Layton, M. W. Ohland and M. K. Orr, "Student demographics and outcomes in electrical and mechanical engineering," in Proceedings of the 2013 IEEE/ASEE Frontiers in Education Annual Conference, Oklahoma City, OK, 2013.

[17] B. L. Yoder, Engineering by the Numbers, Washington, DC: American Society for Engineering Education, 2017.

[18] R. Levitz and L. Noel, "Connecting students to institutions: Keys to retention and success.," in The freshman year experience: Helping students survive and succeed in college, M. L. Upcraft and J. N. Gardner, Eds. San Francisco \& Oxford: Jossey-Bass, 1989, pp. $65-81$. 